\title{
Role of Supplementations of Combined Vitamins with Minerals on lodine Status in Pregnant Women in Bulgaria
}

\author{
Anna-Maria Borissova ${ }^{1,2}$, Ludmila Ivanova ${ }^{2}$, Boyana Trifonova ${ }^{1,2, ~ *, ~ L i l i a ~ D a k o v s k a ~}{ }^{1}$, \\ Eugenia Mihailova ${ }^{1}$, Mircho Vukov ${ }^{1}$ \\ ${ }^{1}$ Clinic of Endocrinology, University Hospital Sofiamed, Sofia, Bulgaria \\ ${ }^{2}$ Faculty of Medicine, Sofia University Saint. Kliment Ohridski, Sofia, Bulgaria
}

Email address:

boianatri@abv.bg (B. Trifonova)

${ }^{*}$ Corresponding author

\section{To cite this article:}

Anna-Maria Borissova, Ludmila Ivanova, Boyana Trifonova, Lilia Dakovska, Eugenia Mihailova, Mircho Vukov. Role of Supplementations of Combined Vitamins with Minerals on Iodine Status in Pregnant Women in Bulgaria. International Journal of Diabetes and Endocrinology. Vol. 5, No. 3, 2020, pp. 47-53. doi: 10.11648/j.ijde.20200503.13

Received: September 10, 2020; Accepted: October 6, 2020; Published: October 13, 2020

\begin{abstract}
Underestimating the risk of iodine deficiency among the population and its impact on high risk groups such as pregnant women and children creates a serious problem for the health care system. The aim of the present study is to establish the current iodine status in pregnant women in Bulgaria and to clarify the importance of additional supplementation with combined vitamins and minerals (including iodine). Material: We included 537 non selected in advance pregnant women, avarage age $30.49 \pm 5$ years (95\% CI: 30.06 - 30.91), median - 30 (18-47) (95\% CI: 30 - 31). More than 50\% (271/537) of pregnant women took only vitamins with minerals or combined with other medications. Methods: After completing a personal Questionnaire, each pregnant woman followed the study protocol: sample for TSH and TPOAb (ECLIA method) morning urine to determine the iodine concentration by inductively coupled plasma mass spectrometry (ICP-MS); ultrasound examination to determine the volume of the thyroid gland. Results: The mean concentration of iodine in urine for the whole group of pregnant women (n-537) was $181.60 \pm 93.97 \mu \mathrm{g} / \mathrm{L}$, median $170 \mu \mathrm{g} / \mathrm{L}\left(20^{\text {th }}\right.$ percentile $-102 \mu \mathrm{g} / \mathrm{L}, 80^{\text {th }}$ percentile $\left.-248 \mu \mathrm{g} / \mathrm{L}\right)$. According to the criterion "additional supplementation" three groups of pregnant women were formed - A (79, 14.71\%) - not taking anything, B (271, $50.47 \%$ ) - taking combined vitamins with minerals (including iodine), $\mathrm{C}$ (187, 34.82\%) - taking medicines other than vitamins. The highest is the average level of iodine in urine in Group B $-191.08 \pm 95.42 \mu \mathrm{g} / \mathrm{L}$ and the lowest in Group A $-162.91 \pm 93.23$ $\mu \mathrm{g} / \mathrm{L}, \mathrm{P}<0.01$. If combined vitamins with minerals (including iodine) are taken, it will be significantly less common to have low iodine in urine - Group B $-31.1 \%$ against Group A $-53.2 \%, \mathrm{P}<0.033$ i.e. there is a greater chance to normalize the level of iodine in the body. The supplementation with combined vitamins with minerals (including iodine) increased the percentage of pregnant women with over-optimal iodine in urine $(>250 \mu \mathrm{g} / \mathrm{L})-23.3 \%$ against $15.6 \%$ of these not taking combined vitamins with minerals $(\mathrm{P}<0.04)$. No association was found between iodine in urine and thyroid volume, nor with abnormalities in TSH or TPOAb levels. Conclusion: The additional intake of combined vitamins with minerals (including iodine) contributes to the normal level of iodine in urine in pregnant Bulgarian women.
\end{abstract}

Keywords: Supplementation, Iodine in Urine, TSH, TPOAb, Thyroid Volume

\section{Introduction}

Iodine deficiency is a very serious public health problem for every population in the world and especially for pregnant women and young children. Underestimating this problem is a direct threat to public health. Particularly critical is the effect of low iodine intake during pregnancy, due to the proven role of iodine on the development of fetal brain structures. It is not entirely clear whether the consumption of iodized salt alone can ensure the increased iodine needs of pregnant women. Intellectual potential is directly responsible for the formation of nerve tissue. The main substrate for adequate synthesis of 
thyroid hormones is iodine. According to three international organizations - World Health Organization (WHO), International Council for the Control of Iodine Deficiency Disorders (ICCIDD) and United Nations Children's Fund (UNICEF) iodine deficiency at population level is proven when the median iodine concentration in a spot urinary sample in children aged $6-11$ years is $<100 \mu \mathrm{g} / \mathrm{L}$ and in pregnant women is $<150 \mu \mathrm{g} / \mathrm{L}$. The normal range for urinary iodine concentration (UIC) in pregnant women is 150-249 $\mu \mathrm{g} / \mathrm{L}[1,2]$. During pregnancy, iodine requirements increase and the recommended daily intake of iodine is 250 $\mu \mathrm{g}$, unlike non-pregnant women, who have $150 \mu \mathrm{g}$. WHO, UNICEF, ICCIDD (2001) recommend that the daily iodine intake for pregnant women and nursing mothers should be $250 \mu \mathrm{g}$, for children - $90-120 \mu \mathrm{g}$ (for the periods: up to 5 years and 6-11 years), and for adolescents (from 12 years up) and adults - $150 \mu \mathrm{g}$ daily [2-4]. A person's intelligence depends of the development of nerve tissue, and thyroid hormones are essential for its development [5-7]. The aim of the present study is to investigate iodine intake in pregnant women in Bulgaria by examining the effect of supplementation of combined vitamins with minerals (including iodine) and medications in a country with established universal iodization of salt. However, there are also practices of salt intake which are different from Bulgarian iodized salt so it is very important to check the real status of Bulgarian pregnant women.

Study design

A cross-sectional, multicenter population-based study was conducted from September 25 to November 6, 2019 in 10 regions of Bulgaria (Sofia and Sofia region - Samokov, Pirdop; Smolyan and the region; Gotse Delchev; Gabrovo and the region; Troyan-Apriltsi; Burgas and the region; Stara Zagora and the region; Pleven and the region), including small towns and villages from each region or a total of 84 settlements. The regions were not randomly selected. Regions with known iodine deficiency in the past endemic were included, such as Sofia city, Sofia district, Smolyan, Gotse Delchev, Gabrovo, Troyan, as well as regions with iodine sufficiency (non-endemic) - Burgas, Stara Zagora, Pleven and their districts. The study was conducted with the assistance of 104 endocrinologists and gynecologists from the selected areas. They invited over 630 pregnant women to participate in the screening. Of these, 537 pregnant women $(85.23 \%)$ took part.

\section{Material}

We studied 537 pregnant women, average age 30.49 \pm 5 years [95\% CI: 30.06 - 30.91], median - 30 (18 - 47), [95\% CI: $30-31]$. Their distribution by age categories is as follows: $18-$ $22 \mathrm{y}-31(5.78 \%), 23-27 \mathrm{y}-114(21.22 \%), 28-32 \mathrm{y}-214$ (39.86\%), 33 - 37 y - 128 (23.84\%), 38 - 42 y - 46 (8.56\%), 43 - $47 \mathrm{y}-4(0.74 \%)$. It should be noted that $85 \%$ of pregnant women are between 23 and 37 years of age. The examined pregnant women are distributed by trimesters according to the gestational week, as follows: first - 109 (20.3\%), second - 269
(50.1\%), third - $159(29.6 \%)$.

All participants signed an informed consent, confirmed by the local Ethics Commission at Sofiamed University Hospital, and prepared following ethical standards according to the Helsinki-1964 Declaration and its later additions [8].

Each pregnant woman herself filled in a Questionnaire with the assistance of a specially designated medical person from the "face to face" team in order to correctly collect data on pregnancy history, intake of combined vitamins with minerals, (including iodine) other medications by type and dose, available thyroid or other diseases.

Pregnant women were admitted to the screening at random without pre-selection, as $458 / 537(85.28 \%)$ of them took medication [Magnesium supplements - 125 (23.27\%), Acid Folic - 118 (21.9\%), Micronized progesterone - 23 (4.2\%), Iron supplements - 64 (11.9\%), Antispasmodics- 32 (5.9\%), Aspirin - 30 (5.5\%), Low molecular weight heparins - 27 (5.0\%), Levothyroxine - 77 (14.1\%), Methyldopa - 4 (0.7\%)] alone or in various combinations. However, mainly in $50.46 \%$ (271/537) of the cases these were combined preparations containing vitamins and minerals (including iodine) taken alone or together with other medications, following the protocol of gynecologists, thus providing $150 \mu \mathrm{g}$ iodine per day. The most common drugs are magnesium, folic acid and iron (57.1\%), and some other drugs given to individual pregnant women in order to preserve the pregnancy and bring it to a successful delivery antispasmodics, progestin, and anticoagulants. Levothyroxine substitution was found in 77 (14.1\%) pregnant women with a known thyroid disease.

All participants were Caucasian, with no evidence of liver, kidney disease or evidence of malabsorbtion. Pregnant women followed their usual daily routine in the previous months.

\section{Methods}

After completing the personal Questionnaire, the actual weight and height for each pregnant woman were measured. The weight before pregnancy was also registered in the Questionnaire. The body mass index (BMI $-\mathrm{kg} / \mathrm{m}^{2}$ ) before pregnancy and the current one were calculated. Data on dietary supplement use were obtained from the Questionnaire, and women were classified as supplement users (using combined vitamins containing $\geq 150 \mu \mathrm{g}$ iodine/day) and non-supplement users. The cut-off of $150 \mu \mathrm{g}$ was chosen as this is the recommended level for iodine supplementation during pregnancy in many countries and as the most popular combined vitamin with minerals tablets in our country contain $150 \mu \mathrm{g}$ iodine $[9,10]$.

Fasting venous blood was taken from the cubital vein, a sample of fresh morning urine sample was collected, and an ultrasound examination of the thyroid gland was performed.

The main indicators that determine the iodine status are: concentration of urinary iodine, TSH level, thyroid size (volume). The first most important is urinary iodine concentration (UIC), which indicates the intake of iodine with food $(90 \%$ is excreted passively in the urine depending on estimated glomerular filtration rate, eGFR) [11]. Thus, the 
UIC in a sustained diet represents the balance between dietary intake, thyroid iodine extraction, total thyroid hormone depot and GFR.

\subsection{Screening Algorithm}

\subsubsection{Determination of Existing Thyroid Volume Among the Examined Pregnant Women}

In addition to palpation of the cervical region to determine the volume of the thyroid gland, an ultrasound examination was performed with Digital Color Doppler Diagnostic Scanner, C5 Ex (Shenzhen Landwind Medical Industry, China). According to the standard formula, the volume of the thyroid gland in $\mathrm{mL}$ was calculated and it was used in the analyses of Zimmermann MB. et al. and in subsequent years to date $[12,13]$.

\subsubsection{The Laboratory Analysis}

The laboratory analysis of all blood samples was performed in a Central laboratory on the day of taking the blood sample in the morning on an empty stomach. TSH (reference limits 0.27 - $4.2 \mathrm{mIU} / \mathrm{L}$ ) was quantified using the ECLIA-sandwich method of the Cobas e601 analyzer, as well as TPOAb (reference limits $<34 \mathrm{IU} / \mathrm{mL}$ ) by the ECLIA-method of the Cobas e601 analyzer.

\subsubsection{Urinary Iodine Concentration Is Determined}

The pregnant women gave a single portion of the morning fresh midstream urine $\sim 20 \mathrm{ml}$ using clean plastic cups to test iodine. The samples were immediately transported at room temperature in neutral monocuvets to the Central Laboratory (for transport shorter than $8 \mathrm{~h}$, they were transported at room temperature, which does not influence their quality) and the aliquots of all urine samples were frozen at $-20^{\circ}$ until analysis. The next day the frozen samples were transported in special containers to the accredited Limbach laboratory in Heidelberg, Germany. The analysis was performed using the accredited inductively coupled plasma mass spectrometry (ICP-MS) method with the following characteristic: linearity in the range of $0-4000 \mu \mathrm{g} / \mathrm{l}$, precision in the series at $304 \mathrm{mcg} / \mathrm{l} \mathrm{RSD}$ $0.8 \%$, inter-assay $\mathrm{SNU}=304 \mu \mathrm{g} / \mathrm{l}, 15$ shifts, RSD $4.5 \%$; accuracy percentage deviation from adjusted nominal value of the certified reference material SeronormTM Trace Elements urine (SNU) $(304 \mu \mathrm{g} / \mathrm{l}): 4.0 \%$ (data set=4x12), recovery $91 \%$ and $104 \%$. The results are presented in $\mu \mathrm{g} / \mathrm{L}$.

\subsection{The Statistical Analysis}

The statistical analysis was performed using standard SPSS 13.0 for Windows: descriptive statistics (mean, medians, standard deviation), correlation analysis and analysis of variance (ANOVA, post-hoc test - with Bonferroni alpha correction), using parametrical and non-parametrical methods, including - Chi-Square Test, Fisher's Exact Test, Kolmogorov-Smirnov, Shapiro-Wilk Tests, Levene's Test for Equality of Variances, Student's t-test, Kruskal-Wallis test and Mann-Whitney test. All quantitative variables were presented as mean with standard deviation, median or percentage (unless specified otherwise), $\mathrm{p}$ values below 0.05 were accepted as statistically significant.

\section{Results}

The mean value of iodine in urine for the whole group of pregnant women (n-537) was $181.60 \pm 93.97 \mu \mathrm{g} / \mathrm{L}$, and the median (mUIC) was $170 \mu \mathrm{g} / \mathrm{L}(95 \% \mathrm{CI}$ : 161 - 177) and is presented in Table 1 together with its $20^{\text {th }}$ and $80^{\text {th }}$ percentiles

Table 1. Summary mUIC data in the study population of 537 pregnant women.

\begin{tabular}{ll}
\hline Indicator & Value \\
\hline Number of subjects & 537 \\
Median & $170 \mu \mathrm{g} / \mathrm{L}$ \\
$20^{\text {th }}$ percentile & $102 \mu \mathrm{g} / \mathrm{L}$ \\
$80^{\text {th }}$ percentile & $248 \mu \mathrm{g} / \mathrm{L}$ \\
$<100 \mu \mathrm{g} / \mathrm{L}$ & $19.0 \%$ \\
$<50 \mu \mathrm{g} / \mathrm{L}$ & $4.28 \%$ \\
$<20 \mu \mathrm{g} / \mathrm{L}$ & $0.37 \%$ \\
\hline
\end{tabular}

Our results contrast with those of Bath S. C. (2015), which reported UK data for first trimester pregnant women - mean mUIC level $85.3 \mu \mathrm{g} / \mathrm{L}$ (in $42 \%$ pregnants with supplementation - $111 \mu \mathrm{g} / \mathrm{L}$, and in $58 \%$ pregnants without supplementation $-60.9 \mu \mathrm{g} / \mathrm{L}$ ) [14]. On the other hand, iodine deficiency has been reported in fertile women in Asia. According to data from The Nutrition and Health Survey in Taiwan (2013) revealed that the mUIC of non-pregnant women of child-bearing age of 15-44 years was $124 \mu \mathrm{g} / \mathrm{L}$, which was adequate in general, but insufficient according to pregnancy criteria [15].

We divided our pregnant women into three main groups according to the accepted criteria for the level of iodine in urine - low: 1 - $149 \mu \mathrm{g} / \mathrm{L}$; normal: 150 - $249 \mu \mathrm{g} / \mathrm{L}$; over-optimal: 250 - $497 \mu \mathrm{g} / \mathrm{L}$ [16-18], table 2 .

Table 2. Distribution of pregnant women in three main groups according to the level of iodine in urine - low, normal, over-optimal.

\begin{tabular}{lll}
\hline Parameter & Level $(\boldsymbol{\mu g} / \mathbf{L})$ & Number $(\%)$ \\
\hline Low UIC & $1-149$ & $221(41.2)$ \\
Normal UIC & $150-249$ & $211(39.3)$ \\
Over-optimal UIC & $249-497$ & $105(19.6)$ \\
\hline
\end{tabular}

To detail the low level of iodine in urine, another subgroup with level of iodine in urine $\leq 49 \mu \mathrm{g} / \mathrm{L}$ was introduced in table 3 .

Table 3. Subgroup distribution of iodine in urine in the general group of pregnant women.

\begin{tabular}{lllll}
\hline Subgroups & $\leq \mathbf{4 9} \boldsymbol{\mu g} / \mathrm{L}$ & $\mathbf{5 0 - 1 4 9} \boldsymbol{\mu g} / \mathbf{L}$ & $\mathbf{1 5 0 - 2 4 9} \boldsymbol{\mu g} / \mathbf{L}$ & $>\mathbf{2 5 0} \boldsymbol{\mu g} / \mathbf{L}$ \\
\hline Number $(\%)$ & $23(4.28)$ & $198(36.87)$ & $211(39.29)$ & $105(19.55)$ \\
\hline
\end{tabular}

The role of the intake of combined vitamins with minerals (including iodine) during pregnancy was analyzed. In general, combined vitamins usually contain $150 \mu \mathrm{g}$ of iodide. Thus, 4 groups were formed: Group A - pregnant women, who do not take anything (n-79, 14.71\%); Group B - pregnant women, who take combined vitamins with minerals (including iodine) - alone or with other drugs (n-271, 50.37\%); Group C pregnant women, taking any medication but not vitamins (n-187, 34.82\%); Group D - unites pregnant women, who do 
not take vitamins, i.e. Group A + Group C (n-266), table 4.

Table 4. Analysis of the whole group according to the intake of drugs in general and in the subgroups with different levels of iodine in urine.

\begin{tabular}{llllll}
\hline Group/ Indicator & Total & $\begin{array}{l}\text { Group A - not taking } \\
\text { anything (n-79) }\end{array}$ & $\begin{array}{l}\text { Group B-taking vitamins } \\
\text { with minerals (n-271) }\end{array}$ & $\begin{array}{l}\text { Group C - taking other } \\
\text { medications (n-187) }\end{array}$ & $\begin{array}{l}\text { Group D=group A + } \\
\text { group C (n-266) }\end{array}$ \\
\hline Number (\%) & $537(100 \%)$ & $79(14.71 \%)$ & $271(50.47 \%)$ & $187(34.82 \%)$ & $266(49.53 \%)$ \\
Median & 170 & 149 & 175 & 170 & 158 \\
$95 \% \mathrm{CI}$ & $161-177$ & $123-168$ & $166-199$ & $151-185$ & $137-176$ \\
Mean level of UIC \pm SD & $181.61 \pm 93.97$ & $162.91 \pm 93.23$ & $191.08 \pm 95.42$ & $175.31 \pm 90.86$ & $171.66 \pm 91.56$ \\
$<49 \mu \mathrm{g} / \mathrm{L}$ & $\mathrm{n}-23,4.28 \%$ & $\mathrm{n}-8,10.12 \%$ & $\mathrm{n}-8,2.95 \%$ & $\mathrm{n}-7,3.76 \%$ & $\mathrm{n}-15,5.61 \%$ \\
$50-149 \mu \mathrm{g} / \mathrm{L}$ & $\mathrm{n}-198,36.87 \%$ & $\mathrm{n}-35,44.32 \%$ & $\mathrm{n}-92,33.94 \%$ & $\mathrm{n}-71,37.96 \%$ & $\mathrm{n}-106,39.84 \%$ \\
$150-249 \mu \mathrm{g} / \mathrm{L}$ & $\mathrm{n}-211,39.29 \%$ & $\mathrm{n}-25,31.64 \%$ & $\mathrm{n}-109,40.23 \%$ & $\mathrm{n}-77,41.17 \%$ & $\mathrm{n}-102,38.71 \%$ \\
$250+\mu \mathrm{g} / \mathrm{L}$ & $\mathrm{n}-105,19.55 \%$ & $\mathrm{n}-11,13.92 \%$ & $\mathrm{n}-62,22.88 \%$ & $\mathrm{n}-32,17.11 \%$ & $\mathrm{n}-43,16.16 \%$ \\
\hline
\end{tabular}

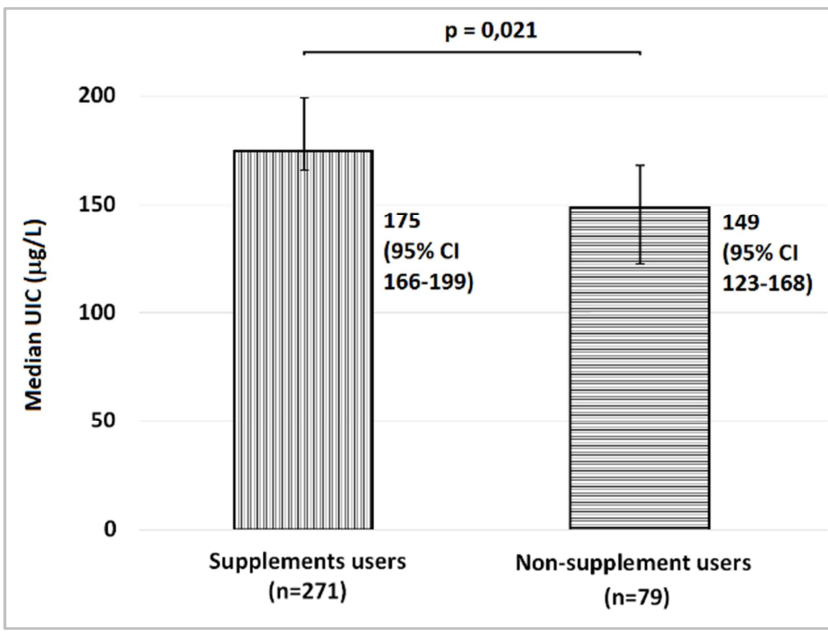

Figure 1. Comparison of median urine iodine concentration between groups $B$ (supplemented) and A (non-supplemented).

As can be seen from Table 3, there are isolated cases with extremely low levels of iodine in urine (n-23, 4.28\%), while the main group are pregnant women with normal or over-optimal levels of iodine in urine (n-316, 58.84\%). The highest is the average value of iodine in urine in pregnant women who take vitamins with minerals - including iodine (Group B) and the lowest is in those pregnant women who do not take anything (Group A). The difference is significant $191.08 \pm 95.42 \mu \mathrm{g} / \mathrm{L}$ for Group B versus $162.91 \pm 93.23 \mu \mathrm{g} / \mathrm{L}$ for Group A $(\mathrm{P}<0.01)$, and in figure 1 we present a comparison of the medians of UIC of these two groups of pregnant women, which also differ significantly $(\mathrm{P}<0.021)$.

In the conditions of different iodine in urine, a comparison of the frequency between the two groups - Group A (does not take anything) and Group B (takes combined vitamins with minerals) was made. A significant difference between them in the conditions of low iodine in urine was found. If you take vitamins with minerals (Group B), you will have low iodine in urine significantly less often, i.e. you will normalize the level of iodine in your body $(36.5 \%$ vs. $54.4 \%), \mathrm{P}<0.033$, table 5 .

Table 5. Comparison between Group A (not supplemented) against Group B (supplemented).

\begin{tabular}{lll}
\hline Medications & $\mathbf{1 - 1 4 9} \boldsymbol{\mu g} / \mathbf{L}$ & $\mathbf{1 5 0 - 2 4 9} \boldsymbol{\mu g} / \mathbf{L}$ \\
\hline Group A -not supplemented n-79 (100\%) & $43(54.43 \%)^{*}$ & $25(31.65 \%)$ \\
Group B - supplemented with vitamins and minerals n-271 (100\%) & $99(36.54 \%)^{*}$ & $11(13.92 \%)$ \\
Total n-350 (100\%) & $142(40.57 \%)$ & $63(40.22 \%)$ \\
\hline
\end{tabular}

$* \mathrm{p}<0.033$ (Chi-Square Tests - Fisher's Exact Test).

When comparing Group C (taking other medications but without vitamins resp. iodine) with the other two groups Group A (not supplemented) and Group B (supplemented with combined vitamins and minerals-including iodine) no significant difference was found (NS).
Group B (supplemented with combined vitamins and minerals-including iodine) showed that in comparison with the other two combined groups $\mathrm{A}+\mathrm{C}$ (both have no vitamin intake) there is a significant difference between low and over-optimal iodine $(\mathrm{P}<0.043)$, table 6 .

Table 6. Comparison of the frequency of the combined Group D=group A and group C (not supplemented) with Group B (supplemented with vitamins and minerals) in different level of iodine in urine.

\begin{tabular}{|c|c|c|c|}
\hline Medications & $1-149 \mu \mathrm{g} / \mathrm{L}$ & $150-249 \mu \mathrm{g} / \mathrm{L}$ & $250-497 \mu \mathrm{g} / \mathrm{L}$ \\
\hline Group $\mathrm{D}=$ Groups $\mathrm{A}+\mathrm{C}$, Not supplemented n-266 (100\%) & $122(45.87 \%)^{*}$ & $102(38.34 \%)$ & $42(15.79 \%)^{*}$ \\
\hline Group B Supplemented with vitamins and minerals n-271 (100\%) & $99(36.54 \%)^{*}$ & $109(40.22 \%)$ & $63(23.24 \%)^{*}$ \\
\hline Total n-537 (100\%) & $221(41.1 \%)$ & $211(39.3 \%)$ & $105(19.6 \%)$ \\
\hline
\end{tabular}

${ }^{*} \mathrm{p}<0.043$ (Chi-Square Tests - Fisher's Exact Test).

Combined vitamins with minerals (including iodine) have a significant effect on the excretion of iodine in the urine. Their intake increases the percentage of pregnant women with over-optimal iodine in urine $(250-497 \mu \mathrm{g} / \mathrm{L})$ - $23.24 \%$ against $15.79 \%$ in the non-supplemented. Conversely, non-intake of combined vitamins with minerals increased the percentage of 
pregnant women with low iodine in urine $(1-149 \mu \mathrm{g} / \mathrm{L})$ $45.87 \%$ vs. $36.54 \%$ for those taking combined vitamins $(\mathrm{P}<$ 0.04, Fisher's Exact Test).

The problem of iodine supplementation has also been studied by Manousou S. et al (2019), who concluded that pregnant women in Sweden have inadequate iodine nutrition. The median UIC was $149 \mu \mathrm{g} / \mathrm{L}(88,253 ; \mathrm{n}=253)$ in supplement users (using supplements containing $\geq 150 \mu \mathrm{g}$ iodine/day) and $85 \mu \mathrm{g} / \mathrm{L}(51,134 ; \mathrm{n}=440)$ in non-supplement users (using no supplements or supplements containing $<150$ $\mu \mathrm{g}$ iodine/day) $(\mathrm{P}<0.001)$. So, women not taking iodine supplements containing $\geq 150 \mu \mathrm{g}$ iodine/day are affected by mild iodine deficiency [19]. The role of iodine in urine on TSH and thyroid volume was further analyzed. The standard for the average thyroid volume in healthy women is $12.4 \pm 3.34$ $\mathrm{mL}(9.06$ - $15.74 \mathrm{~mL})$ [20]. In 2017, Atlas of Thyroid Ultrasonography set an upper normal volume limit for women $<17.4 \mathrm{~mL}$ [21], and the World Health Organization suggests 4.4-18 $\mathrm{mL}$ for normal thyroid volume in women [22].

Table 7 presents the average thyroid volume of the studied pregnant women, which is $8.94 \pm 2.62 \mathrm{~mL}\left(25^{\text {th }}\right.$ percentiles $7.23,75^{\text {th }}$ percentile - 10.37), Median - 8.65 (minimum 0.26, maximum 23.04).

Table 7. TSH level and thyroid volume at the three main levels of iodine in urine in the studied pregnant women.

\begin{tabular}{llll}
\hline Level of UIC & indicator & TSH (mIU/L) & $\begin{array}{l}\text { Volume of thyroid } \\
\text { gland }(\mathbf{m L})\end{array}$ \\
\hline $\begin{array}{l}0-149 \mu \mathrm{g} / \mathrm{L} \\
\text { number }\end{array}$ & & 221 & 221 \\
& Mean & 2.640 & 9.08 \\
& Standard & 1.434 & 2.7 \\
& deviation & 2.460 & 8.70 \\
& Median & 0.05 & 1.43 \\
& Minimum & 9.890 & 21.03 \\
$150-249 \mu \mathrm{g} / \mathrm{L}$ & Maximum & & \\
number & & 211 & 211 \\
& Mean & 2.926 & 8.88 \\
& Standard deviation & 2.327 & 2.69 \\
& Median & 2.495 & 8.56 \\
& Minimum & 0.02 & 0.26 \\
$250-497 \mu \mathrm{g} / \mathrm{L}$ & Maximum & 24.150 & 23.04 \\
number & & & \\
& & 105 & 105 \\
& Mean & 2.774 & 8.77 \\
& Standart deviation & 1.330 & 2.26 \\
& Median & 2.605 & 8.65 \\
& Minimum & 0.32 & 3.89 \\
& Maximum & 7.220 & 18.38 \\
\hline
\end{tabular}

\section{Discussion}

It is well known that the fetus during the first and part of the second trimester does not have its own production of thyroid hormones and it receives them from the mother. During this period, the production of maternal thyroid hormones increases, which requires more iodine - a substrate for the synthesis of thyroid hormones. Thyroid dysfunction is already thought to develop with urinary iodine excretion below $50 \mu \mathrm{g}$ [23]. In our study, the mean TSH level was $2.77 \pm 1.82 \mathrm{mIU} / \mathrm{L}$, Median
$2.53(0.020-24.15)$, Percentiles $\left(20^{\text {th }}-1.61 ; 25^{\text {th }}-1.75 ; 50^{\text {th }}-\right.$ $\left.1.53 ; 75^{\text {th }}-3.43 ; 80^{\mathrm{s}}-3.73\right)$. The cases with low level of iodine in urine $(\leq 49 \mu \mathrm{g} / \mathrm{L})$ are few $-23 / 537$ (4.28\%). In this group, the level of TSH is within the norm of $2.59 \pm 1.43 \mathrm{mIU} / \mathrm{L}$ and no significant difference was found in pregnant women with a normal level of iodine in urine (150 - $249 \mu \mathrm{g} / \mathrm{L})-2.91 \pm 2.32$ $\mathrm{mIU} / \mathrm{L}$, NS. Separately for each trimester, the mean level of $\mathrm{TSH}$ in the group with iodine in urine $\leq 49 \mu \mathrm{g} / \mathrm{L}$ (first -

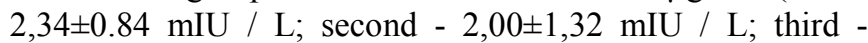
$3,36 \pm 1,50 \mathrm{mIU} / \mathrm{L}$ ) did not differ significantly from the level of the hormone in pregnant women with normal iodine in urine, NS.

The level of TSH in the groups with different iodine in urine is presented in Table 7 and no significant difference was found in the three main levels - low, normal and over-optimal iodine in urine. About $19.55 \%$ of the pregnant women had higher levels of iodine in urine $(250-497 \mu \mathrm{g} / \mathrm{L})$. It is known that higher iodine intake can lead to thyroid dysfunction (reversible inhibition of function - Wolff-Chaikoff effect or iodine-induced thyrotoxicosis - Jod-Basedow), goiter formation, autoimmune thyroid disease. A healthy individual can tolerate iodine levels of $600-1100 \mu \mathrm{g}$ iodine /per day without side effects [24-26].

It should be borne in mind that TSH is a good indicator of iodine status in newborns but not in pregnant women [27]. Our results regarding the level of TSH and the thyroid volume in the three groups of pregnant women according to the concentration of iodine in urine - with low $(<149 \mu \mathrm{g} / \mathrm{L})$, with normal (150 $249 \mu \mathrm{g} / \mathrm{L})$ and with over-optimal ( $>250 \mu \mathrm{g} / \mathrm{L})$ showed that there is no significant difference in the indicated parameters between the separate groups (Table 7). No statistically significant correlation was found between iodine in urine and TSH levels, as well as between iodine in urine and thyroid volume. There was no difference in TSH levels between those taking or not taking combined vitamins with minerals (including iodine) - 2.64 $\pm 1.34 \mathrm{mIU} / \mathrm{L}$ against $3.03 \pm 2.05 \mathrm{mIU}$ / L, NS.

Women living in a population with a median UIC at or above $100 \mu \mathrm{g} / \mathrm{L}$ are not in need of iodine supplementation in pregnancy, but if the population median UIC is below $100 \mu \mathrm{g} /$ $\mathrm{L}$, pregnant women should take iodine-containing supplementation [28].

Lombardi FA. et al. (2013) noted an increase in the incidence of Hashimoto's Thyroiditis with the inclusion of iodine prophylaxis, which we often find in our practice, but it is more transient and is observed in the first years after the introduction of universal salt iodization preventive strategy [29].

In the present material the frequency of cases with positive TPOAb is $10.5 \%$ in the examined pregnant women. The distribution of TPOAb according to the level of iodine in urine did not show significant differences in the three groups - with low iodine in urine $(<149 \mu \mathrm{g} / \mathrm{L})-47.2 \%$, with normal iodine in urine $(150-249 \mu \mathrm{g} / \mathrm{L})-30.9 \%$ and with over-optimal iodine in urine $(>250 \mu \mathrm{g} / \mathrm{L})-21.8 \%$, NS. It is noteworthy that almost half of the cases with elevated thyroid antibodies (TPOAb) are in pregnant women with low iodine in urine and even the lowest is in those with over-optimal levels of iodine 
in urine, which has been reported by other authors [3].

The thyroid size is a very useful indicator for assessing the severity of iodine deficiency, but it is also used to control the initiation of a preventive strategy for control of iodine deficiency [30]. Our result showed that the average thyroid volume for the whole group of pregnant women was $8.94 \pm 2.62 \mathrm{~mL}$, median 8.65 (minimum 0.26 - maximum 23.04). According to the accepted normal limits of WHO (4.4 to $18 \mathrm{~mL}$ ), only in $2.0 \%$ of our women $(\mathrm{n}-11)$ the volume is less $(0.26-4.27 \mathrm{~mL})$, and in $0.7 \%$ of pregnant women $(\mathrm{n}-4)$ it is slightly above the upper limit $(20.18-23.04 \mathrm{~mL})$. All other pregnant women $97.2 \%(n-522)$ have a normal thyroid volume When comparing the volume of the thyroid gland in the three groups - with low iodine in urine $(<149 \mu \mathrm{g} / \mathrm{L})$, with normal iodine in urine $(150-249 \mu \mathrm{g} / \mathrm{L})$ and with over-optimal iodine in urine $(>250 \mu \mathrm{g} / \mathrm{L})$ no significant difference (NS) was found, table 7. The level of iodine intake according to the median urinary iodine concentration (mUIC) is distributed as follows: severe iodine deficiency at a median $<20 \mu \mathrm{g} / \mathrm{L}$, moderate at a median in the range of $20-49 \mu \mathrm{g} / \mathrm{L}$, mild at a median in the range of $50-99.9 \mu \mathrm{g} / \mathrm{L}$ [2]. In the presented Bulgarian data (Table 1) very low iodine intake, iodine in urine $<20 \mu \mathrm{g}$ / L is present in only $0.37 \%$ (2 pregnant women), moderate - in 3.91\% (21 women) and mild in $14.5 \%$ (78 pregnant women) or the relative share of persons with a value below the lower reference limit is established at $18.9 \%$ (102 women).

According to WHO / UNICEF / ICCIDD, the criteria for eliminating iodine deficiency are:

1. Over $90 \%$ of households use iodized salt. Bulgaria is officially listed among the countries with $\geq 90 \%$ iodized salt in households [31].

2. Iodine in urine $<100 \mu \mathrm{g} / \mathrm{L}$ is present in $<50 \%$ of the studied cases. Bulgaria is far from this value as far as pregnant women are concerned - only in $18.99 \%$ the iodine in urine is $<100 \mu \mathrm{g} / \mathrm{L}$.

3. Iodine in urine $<50 \mu \mathrm{g} / \mathrm{L}$ is present in $<20 \%$ of the studied cases. Bulgaria is also far from this value - only $4.28 \%$.

\section{Conclusion}

Thus, we can say with full confidence that in Bulgaria the iodine deficiency has been eliminated and our pregnant women are in good condition in this regard. One of the reasons is the universal iodine prophylaxis introduced in 1993, which guarantees adequate iodine intake for the entire population, including women of childbearing age born after the introduction of the mass use of iodized salt. Despite the successful mass iodine prophylaxis in Bulgaria by iodizing salt for food purposes, it is obvious that during pregnancy it is important to substitute with combined vitamins with minerals (containing iodine), which will provide sufficient for this period additional intake of iodide. This can maintain a normal urinary iodine concentration during pregnancy and ensure adequate iodine status for the mother and normal fetal development.

\section{Conflicts of Interests}

All the authors do not have any possible conflicts of interest.

\section{Acknowledgements}

The authors thank the endocrinologists and obstetrician/gynecologists who provided local support: V. Jotova (Troyan), S. Dimitrova (Gabrovo), Anchev (Gabrovo), Mitev (Gabrovo), A. Popov (Goce Delchev), A. Andreev (Samokov), E. Apostolova (Smolyan), M. Hubshev (Smolyan), S. Dimitrov (Pirdop), R. Naumovska (Pleven), M. Manuelyan (Burgas), K. Kirovakov (Burgas), T. Gabrovska (Burgas), K. Venkova (Sofia), M. Angelova (Stara Zagora), R. Velev (Sofia), I. Sigridov (Sofia), B. Bogoslovova (Sofia)... total 104 specialists in the country. Technical support: T. Kornilova (Sofia), Z. Metodieva (Sofia), J. Georgieva (Sofia), H. Atanasova (Burgas), I. Ilieva (Stara Zagora).

This work was supported by grants from the Bulgarian Society of Endocrinology as part of the National Epidemiological Program for Pregnant Women in Bulgaria 2019.

\section{References}

[1] World Health Organization. (2004). Iodine status worldwide: WHO global database on iodine deficiency. Geneva.

[2] WHO, UNICEF, ICCIDD. (2001). Assessment of iodine deficiency disorders and monitoring their elimination. A guide for programme managers, 2nd ed. World Health Organization, Geneva.

[3] World Health Organization. (2007). Assessment of iodine deficiency disorders and monitoring their elimination: a guide for programme managers, $3 \mathrm{rd} \mathrm{ed}$. WHO.

[4] World Health Organization, UNICEF, ICCIDD. (2008). Assessment of iodine deficiency disorders and monitoring their elimination. A guide for programme managers, Third edition, updated $1^{\text {st }}$ September 2008 .

[5] Delange F. (2000). The role of iodine in brain development. Proc Nutr Soc 59: 75-79.

[6] de Escobar G. M, Obregon MJ, Escobar del Rey F. (2000). Is neuropsychological development related to maternal hypothyroidism or to maternal hypothyroxinemia? J Clin Endocrinol Metab 85: 3975-3987.

[7] Bernal J. (2005). Thyroid hormones and brain development. Vitam Horm 71: 95-122.

[8] World Medical Association (2013). "Declaration of Helsinki: Ethical Principles for Medical Research Involving Human Subjects". JAMA. 310 (20): 2191-2194. doi: 10.1001/jama.2013.28105.

[9] Lazarus J, Brown RS, Daumerie C, Hubalewska-Dydejxzyk A, Negro R, Vaidya B. (2014). 2014 European Thyroid Association guidelines for the management of subclinical hypothyroidism in pregnancy and in children. Eur Thyroid J 3 (2): 76-94. https://doi.org/10.1159/00036 2597. 
[10] Alexander EK, Pearce EN, Brent GA, Brown RS, Chen H, Dosiou C, Grobman WA, Laurberg P, Lazarus JH, Mandel SJ, Peeters RP. and Sullivan S. (2017). 2017 Guidelines of the American Thyroid Association for the diagnosis and management of thyroid disease during pregnancy and the $\begin{array}{llll}\text { postpartum. } & \text { Thyroid } 27 & \text { (3): } & 315-389 .\end{array}$ https://doi.org/10.1089/thy.2016.0457.

[11] Soldin OP. (2002). Controversies in urinary iodine determinations. Clin Biochem 35: 575-579.

[12] Brunn J, Block U, Ruf G, Bos I, Kunze WP, Scriba PC. (1981). Volumetric analysis of thyroid lobes by real-time ultrasound. Dtsch Med Wochenschr. 106: 1338-1340.

[13] Zimmermann MB, Hess S. Y, Molinari L, de Benoist B, Delange F, Braverman L. E, Fujieda K, Ito Y, Jooste P. L, Moos K, Jooste P. L, Pearce E. N Pretell E. A, Shishiba Y. (2004). New reference values for thyroid volume by ultrasound in iodine sufficient school children: a World Health Organization / Nutrition for Health and Development Iodine Deficiency Study Group Report. Am J Clin Nutr 79: 231-237.

[14] Bath S. C. and Rayman M. P. (2015). A review of the iodine status of UK pregnant women and its implications for the offspring. Environ Geochem Health. 37 (4): 619-629.

[15] Huang C-J, Tseng C-L, Chen H-S, Hwu C-M, Tang K-T, Won J. G-S, Shih C-S, Yeh C-C, Yang C-C, Wang F-F. (2020). Iodine nutritional status of pregnant women in an urban area of northern Taiwan in 2018. PLOS ONE, May 15, 1-12. https://doi.org/10.1371/journal.pone.0233162.

[16] Mortimer RH, Galligan JP, Cannell GR, Addison RS, Roberts MS. (1996). Maternal to fetal thyroxine transmission in the human term placenta is limited by inner ring deiodination. J Clin Endocrinol Metab 81: 2247-2249.

[17] Burrow GN, Fisher DA, Larsen PR. (1994). Maternal and fetal thyroid function. N Engl J Med 331: 1072-1078.

[18] Biban B. G, Lichiardopol C. (2017). Iodine Deficiency, Still a Global Problem? Current Health Sciences Journal Vol. 43, No. 2, April-June.

[19] Manousou S, Andersson M, Eggertsen R, Hunziker S, Hulthen L, Nystrom H. F. (2019). Iodine deficiency in pregnant women in Sweden: a national cross-sectional study. European Journal of Nutrition, Published online: 15 October; https://doi.org/10.1007/s00394-019-02102-5.

[20] Boyanov M, Vidinov K. (2011). Ultrasound of the cervical region in the practice of the endocrinologist. Pages 25-32. Central Medical Library, Medical University - Sofia, Bulgaria.

[21] Halenka M, Frysak Z. (2017). Atlas of Thyroid Ultrasonography. 2.2. US Features of Diffuse goiter. Sringer Int. Publishing AG, Cham, Switzerland.

[22] World Health Organization. (1994). Indicators for assessing iodine deficiency disorders and their control through salt iodization. Geneva, Switzerland. WHO [Document No WHO/NUT 94.6].

[23] Azizi F, Smyth P. (2009). Breastfeeding and maternal and infant iodine nutrition. Clin. Endocrinol. 70, 803-809.

[24] WHO. Assessment of iodine deficiency disorders and monitoring their elimination. A guide for programme managers. 2nd ed. World Health Organisation, International Council for Control of Iodine Deficiency Disorders, United Nations Children's Fund; 2007.

[25] Rhee SS, Braverman LE, Pino S, He X, Pearce EN. (2011). High iodine content of Korean seaweed soup: a health risk for lactating women and their infants. Thyroid 21: 927-928.

[26] Chung HR, Shin CH, Yang SW, Choi CW, Kim BI. (2009). Subclinical hypothyroidism in Korean preterm infants associated with high levels of iodine in breast milk. J Clin Endocrinol Metab 94: 4444-4447.

[27] de Escobar G. M, Obregon MJ, del Rey F E. (2004). Role of thyroid hormone during early brain development. Eur J Endocrinol 151: U25-U37.

[28] Andersen S. L, Laurberg P. (2016). Iodine Supplementation in Pregnancy and the Dilemma of Ambiguous Recommendations. Eur Thyroid J. 5: 35-43.

[29] Lombardi F. A, Fiore E, Tonacchera M. (2013). The effect of voluntary iodine prophylaxis in a small rural community: the pescopagano survey 15 years later. The Journal of Clinical Endocrinology \& Metabolism. 98 (3): 1031-1039.

[30] Gorstein J. L, Bagriansky J, Pearce E. N, Kupka R, Zimmermann M. B. (2019). Estimating the Health and Economic Benefits of Universal Salt Iodization Programs to correct Iodine Deficiency Disorders. Thyroid DOI: 10.1089/thy.2019.0719, page 1-26.

[31] UNICEF, State of the World's Children. (2017). Global Experience of with salt iodization: percentage of households currently cosuming iodized salt. 